\title{
Studies on immune response to Newcastle disease virus in broiler chickens fed with Lactobacillus reuteri PIA16 isolated from the gut of indigenous chicken of Assam, India
}

\author{
Gaichamdinliu Gonmei ${ }^{1}$, Deben Sapcota ${ }^{1}$, Girin Kumar Saikia ${ }^{2}$, Pankaj Deka ${ }^{2}$, Joga Dev Mahanta ${ }^{1}$, Niranjan Kalita ${ }^{1}$, \\ Bibeka Nanda Saikia ${ }^{3}$ and Jitendra Kumar Talukdar ${ }^{1}$
}

1. Department of Poultry Science, College of Veterinary Science, Assam Agricultural University, Assam, India;

2. Department of Animal Microbiology, College of Veterinary Science, Assam Agricultural University, Assam, India;

3. Department of Animal Nutrition, College of Veterinary Science, Assam Agricultural University, Assam, India.

Corresponding author: Gaichamdinliu Gonmei, e-mail: drgaichamgonmei@yahoo.com

Co-authors: DS: debensapcota@yahoo.com, GKS: saikiagk@yahoo.com, PD: drpankajaau@gmail.com,

JDM: mahantajd@gmail.com, NK: niranjankalita@gmail.com, BNS: bibekas.saikia5@gmail.com, JKT: kjitendra772@gmail.com

Received: 20-03-2019, Accepted: 01-07-2019, Published online: 15-08-2019

doi: 10.14202/vetworld.2019.1251-1255 How to cite this article: Gonmei G, Sapcota D, Saikia GK, Deka P, Mahanta JD, Kalita N, Saikia BN, Talukdar JK (2019) Studies on immune response to Newcastle disease virus in broiler chickens fed with Lactobacillus reuteri PIA16 isolated from the gut of indigenous chicken of Assam, India, Veterinary World, 12(8): 1251-1255.

\begin{abstract}
Background and Aim: The chicken gut harbors microflora which impacts the health, production performance and immune response against pathogens. Assam local chickens reared under natural conditions are known to possess high immunocompetence which may be attributable to its gut microbiota make-up. This study aimed to investigate the individual effect of two strains of Lactobacillus reuteri PIA16 isolated separately from cecum and jejunum of Assam indigenous chicken on the immunity of broiler chickens against Newcastle disease virus (NDV) when fed singly and in combination with a prebiotic.
\end{abstract}

Materials and Methods: A total of 240 birds (48 per group) were vaccinated with Lasota strain of NDV on the $5^{\text {th }}$ and $21^{\text {st }}$ day of age. Blood samples were collected before and after immunization against ND for the detection of humoral antibody response by hemagglutination inhibition test. The cell-mediated immune (CMI) response was estimated through response to phytohemagglutinin-P (PHA-P) and expressed as web index.

Results: A significant influence on the immune response to NDV was observed in all the L. reuteri PIA16 as well as mannan oligosaccharide (MOS) supplemented groups revealing higher antibody titer than the control counterpart. The CMI response revealed a better cutaneous basophilic hypersensitivity response to PHA-P in the treated groups than the control.

Conclusion: Enhancement in immunity was perceived in the broilers fed with L. reuteri PIA16 and in combination with MOS due to the stimulation of the host's humoral and CMI response by the probiotics and prebiotics used.

Keywords: hemagglutination inhibition, Lactobacillus reuteri PIA16, mannan oligosaccharide, Newcastle disease, phytohemagglutinin-P, probiotics.

\section{Introduction}

Newcastle disease (ND) is an infectious and one of the most devastating diseases affecting the poultry which causes very high mortality in chickens and huge productivity losses. To combat diseases, immune status of the chicken is an important factor. The chicken intestine harbors a diverse microflora consisting of both beneficial and pathogenic microorganisms [1]. Colonization of chicken intestine by commensal bacteria begins right after hatch and these bacteria interact closely with cells within the chicken gut-associated lymphoid tissue [2]. This resident microbiota plays a pivotal role in developing the immune system repertoire [3].

Copyright: Gonmei, et al. Open Access. This article is distributed under the terms of the Creative Commons Attribution 4.0 International License (http://creativecommons.org/licenses/ by/4.0/), which permits unrestricted use, distribution, and reproduction in any medium, provided you give appropriate credit to the original author(s) and the source, provide a link to the Creative Commons license, and indicate if changes were made. The Creative Commons Public Domain Dedication waiver (http:// creativecommons.org/publicdomain/zero/1.0/) applies to the data made available in this article, unless otherwise stated.
The use of probiotics, prebiotics, and symbiotics in poultry nutrition is in vogue as they effectively combat the negative impact of stress or pathogens in poultry. They enrich certain bacterial population in the digestive system which has the potential to reduce chances of infection in poultry and subsequent contamination to poultry products. Probiotics are live microorganisms which, when administered in adequate amounts, confer a health benefit on the host as defined by the FAO/WHO [4]. Probiotics beneficially alter the intestinal microflora balance, inhibit the growth of harmful bacteria, promote good digestion, boost immune function, and increase resistance to infection [5]. Significant enhancement in the immune response was observed in chicken resulting from early colonization of the intestine by probiotic containing Lactobacillus acidophilus and Bifidobacterium bifidum [6]. The various species commonly used for probiotic preparations include Lactobacillus bulgaricus, L. acidophilus, Lactobacillus casei, Lactobacillus helveticus, Lactococcus lactis, Lactobacillus salivarius, Lactobacillus plantarum, Streptococcus 
thermophilus, Enterococcus faecium, Enterococcus faecalis, Bifidobacterium spp., Bacillus subtilis, Aspergillus oryzae, Saccharomyces cerevisiae, and Escherichia coli [7-10]. Recently, potential role for probiotics from fungi as natural growth promoter and effective alternative to antibiotics in broiler production has been reported [11]. Similar mechanism of action of probiotics is seen in prebiotics. Gibson et al. [12] defined prebiotic as a selectively fermented ingredient that allows specific changes, both in the composition and/or activity in the gastrointestinal microflora that confers benefits on host well-being and health. Mainly prebiotics are small fragments of carbohydrates and commercially available as oligosaccharides of galactose, fructose, or mannose [13]. Supplementation of either probiotic or prebiotic or both has been reported to improve digestibility and growth performance in broiler chickens [14]. Further, combination of various probiotics when supplemented to layer hens diet increased egg weight, feed efficiency, eggshell quality, decreased cholesterol levels, and increased unsaturated fatty acids in yolk [15].Native breeds of chicken are known for its high immunocompetence, hardiness, better meat quality, desirable taste and flavor of eggs, and meat compared to commercial broilers [16]. Relatively, they have a capacity to resist disease, ability to utilize low-quality feed and their products are preferred by consumers [17]. Assam local chickens reared under natural conditions are also known to possess disease resistance capacity [18].

The gut microflora of Assam local chickens may, therefore, possess certain beneficial microflora to play certain roles in improving the gut immune system. On this context, Lactobacillus reuteri PIA16 was isolated from the gut of Assam local chicken for the study and aimed at evaluating the immune response against ND virus (NDV) of the broiler chicken when fed with $L$. reuteri PIA16 singly and in combination with a prebiotic.

\section{Materials and Methods}

\section{Ethical approval}

The study was approved by the Institutional Animal Ethics Committee, Assam Agricultural University, Assam, India.

\section{Isolation of Lactobacillus strains}

Two strains of Lactobacillus were isolated from the different gut regions of Assam indigenous chicken, i.e., ACE5 (cecum) and AJ3 (jejunum) which were characterized by $16 \mathrm{~S}$ rRNA gene sequencing and BLAST analysis. Genetic identity of $99.72 \%$ with $L$. reuteri was found for both the strains. The identified isolate $L$. reuteri was registered as $L$. reuteri PIA16 under GenBank, National Centre for Biotechnology Information, India.

These strains were treated as two individual entities and were used for in vivo growth bioassay where it was fed singly and in combination with a prebiotic. As premix, 20\% of daily ration required for broilers was autoclaved and inoculated with $20 \%$ of ACE5 and AJ3 broth culture separately and incubated for $37^{\circ} \mathrm{C}$ for $48 \mathrm{~h}$ to facilitate fermentation. Due to readily available source of energy in feed sample, the count of Lactobacillus in fermented feed increased to $1.85 \times 10^{8} \mathrm{CFU} / \mathrm{g}$ and $1.89 \times 10^{8} \mathrm{CFU} / \mathrm{g}$ of fermented feed for ACE5 and AJ3, respectively, which was used in a feeding trial. Mannan oligosaccharide (MOS) was used for the experiment at $0.25 \%$ as the prebiotic [19].

A total of 240day-old broiler chicks (Cobb) were randomly distributed into five dietary treatments of eight replicates with six chicks in each replicate reared under cage system for 35 days. The experimental design consisted of $\mathrm{T}_{1}$ (Control) - basal diet (mash feed), $\mathrm{T}_{2}-\mathrm{T}_{1}+1.85 \times 10^{8}$ CFU of L. reuteri PIA16 (ACE5) $/ \mathrm{g}$ fermented feed, $\mathrm{T}_{3}-\mathrm{T}_{1}+1.89 \times 10^{8}$ CFU of $L$. reuteri PIA16 (AJ3)/g fermented feed, $\mathrm{T}_{4}-\mathrm{T}_{2}+\mathrm{MOS}$ at $0.25 \%$, and $\mathrm{T}_{5}-\mathrm{T}_{3}+\mathrm{MOS}$ at $0.25 \%$ of feed. Probiotic and prebiotic feeding was from the $1^{\text {st }}$ day of age up to 35 days. The environmental conditions during the experimental period ranged from 26 to $32^{\circ} \mathrm{C}$ with relative humidity of $65-95 \%$.

\section{Humoral immune response}

The humoral immune response was studied by estimating the ND-hemagglutination inhibition (HI) antibody titers by HI test. The birds were immunized with ND Lasota strain on the $5^{\text {th }}$ and $21^{\text {st }}$ day. Blood samples were collected from 10 broilers per treatment groups for the determination of antibody titer against NDV HI test on day of vaccination and $7^{\text {th }}, 14^{\text {th }}, 21^{\text {st }}$, and $28^{\text {th }}$ day of post-vaccination (DPV).

To determine HI titers of the sera samples collected from vaccinated chickens, HI tests were performed using Lasota strain of NDV as per the standard methods described in OIE [20]. Briefly, the 4 HA units of Lasota strain of NDV in equal volume $(25 \mu \mathrm{l})$ were added to each serum dilution and incubated at $37^{\circ} \mathrm{C}$ for $45 \mathrm{~min}$. Thereafter, $1 \%$ of chicken $\mathrm{RBC}$ in $25 \mu \mathrm{l}$ volume was added to each well and incubated at $37^{\circ} \mathrm{C}$ for $15 \mathrm{~min}$. The reciprocal of the last serum dilution showing inhibition of hemagglutination of the 4 hemagglutinin units of the NDV was considered as the HI antibody titer of the serum ( $\log _{2}$ value of $\mathrm{HI}$ titer).

\section{Cell-mediated immune (CMI) response}

CMI response was estimated through response to phytohemagglutinin-P (PHA-P) and expressed as a web index. This method was devised by Corrier and De Loach [21]. At 30 days of age, the solution of PHA-P at $0.01 \mathrm{mg} / 0.05 \mathrm{ml}$ of sterile was injected intradermally in the interdigital space of 3-4 digits of the right foot, and the skin thickness was measured before and after $24 \mathrm{~h}$ of injection. The left foot received a similar amount of sterile phosphate-buffered saline (PBS) and served as control, and the difference in skin thickness between injected, and control foot was taken as foot web index. The web swelling of both the feet was measured $24 \mathrm{~h}$ after injection by micrometer and the in vivo response to PHA-P was expressed as web index. 
Table-1: Humoral immune response ( $\log _{2}$ value of $\mathrm{HI}$ titer) to NDV in broiler chickens under different dietary treatments.

\begin{tabular}{|c|c|c|c|c|c|}
\hline \multirow[t]{2}{*}{ Age } & \multicolumn{5}{|c|}{ Treatment groups } \\
\hline & $\mathrm{T}_{1}$ (Control) & $T_{2}\left(T_{1}+\right.$ ACE5 $)$ & $T_{3}\left(T_{1}+A J 3\right)$ & $T_{4}\left(T_{2}+\right.$ MOS $)$ & $T_{5}\left(T_{3}+\right.$ MOS $)$ \\
\hline Day old & $2.50^{\mathrm{a}} \pm 0.17$ & $2.60^{a} \pm 0.16$ & $2.70^{\mathrm{a}} \pm 0.15$ & $2.70^{a} \pm 0.15$ & $2.70^{\mathrm{a}} \pm 0.15$ \\
\hline $5^{\text {th }} d a y$ & $2.10^{\mathrm{a}} \pm 0.10$ & $2.10^{\mathrm{a}} \pm 0.10$ & $2.10^{\mathrm{a}} \pm 0.10$ & $2.10^{\mathrm{a}} \pm 0.10$ & $2.00^{a} \pm 0.00$ \\
\hline $7^{\text {th }}$ DPV* & $4.60^{a} \pm 0.16$ & $5.00^{\mathrm{ab}} \pm 0.21$ & $5.20^{b} \pm 0.20$ & $5.40^{b} \pm 0.16$ & $5.40^{b} \pm 0.16$ \\
\hline $14^{\text {th }}$ DPV & $5.10^{a} \pm 0.18$ & $5.50^{\mathrm{ab}} \pm 0.22$ & $5.70^{b} \pm 0.15$ & $5.80^{b} \pm 0.13$ & $5.90^{b} \pm 0.10$ \\
\hline $21^{\text {st }}$ DPV & $5.60^{a} \pm 0.16$ & $6.10^{\mathrm{ab}} \pm 0.23$ & $6.30^{b} \pm 0.21$ & $6.30^{\mathrm{b}} \pm 0.21$ & $6.40^{b} \pm 0.16$ \\
\hline $28^{\text {th }}$ DPV & $5.20^{a} \pm 0.13$ & $5.90^{\mathrm{b}} \pm 0.18$ & $6.00^{\mathrm{b}} \pm 0.26$ & $6.10^{\mathrm{b}} \pm 0.18$ & $6.20^{\mathrm{b}} \pm 0.20$ \\
\hline
\end{tabular}

*DPV = Day of post-vaccination; abMeans bearing same superscripts in a row do not differ significantly $(p \leq 0.05)$.

$\mathrm{HI}=$ Hemagglutination inhibition, NDV = Newcastle disease virus, MOS = Mannan oligosaccharide

Foot web index (FWI) was calculated as follows: $\mathrm{CMIR}=(\mathrm{R} 2-\mathrm{R} 1)-(\mathrm{L} 2-\mathrm{L} 1)$

Where,

$\mathrm{R} 2=$ Thickness after $24 \mathrm{~h}$ of PHA-P injection

$\mathrm{R} 1=$ Thickness before injection of PHA-P

L2 $=$ Thickness after $24 \mathrm{~h}$ of PBS injection

L1 = Thickness before injection of PBS.

\section{Statistical analysis}

The data obtained were statistically analyzed with one-way analysis of variance and Duncan's multiple range tests to elucidate differences among the treatment groups using the software SAS 9.3 version. Statements of statistical significance were based on $\mathrm{p}<0.05$.

\section{Results}

Significant influence on the immune response to ND virus through dietary supplement of Lactobacillus with or without prebiotic was observed. The $\log 2$ ND-HI antibody titer did not differ significantly $(p>0.05)$ among different dietary groups till the $5^{\text {th }}$ day of pre-immunization and remained in the range

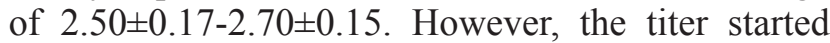
increasing in all the dietary groups, and this trend continued till the $21^{\text {st }}$ DPV and, thereafter, declined (Table-1). Nonetheless, the titer levels of all the L. reuteri PIA16 fed groups were found higher than that of the control group. When L. reuteri PIA16 was fed along with MOS, the titer level reached to the highest level of $6.40 \pm 0.16$ as recorded on the $21^{\text {st }} \mathrm{DPV}$ in $\mathrm{T}_{5}$ group.

Results of CMI response through PHA-P stimulation after $24 \mathrm{~h}$ are depicted in Figure-1. There was no significant $(\mathrm{p}>0.05)$ difference in the cutaneous basophilic hypersensitivity $(\mathrm{CBH})$ response among the five groups, but higher $\mathrm{CBH}$ response was observed in all $L$. reuteri PIA 16 and MOS-fed groups compared to control at 30 days of age. The mean skin thickness values in response to PHA-P in different dietary groups increased marginally due to $L$. reuteri PIA16 and MOS feeding. However, the increase was insignificant among all the five dietary groups (Figure-1).

\section{Discussion}

The positive effect of feeding L. reuteri PIA16 on immune responses was in agreement with other authors [6,22-24] who observed increased antibody

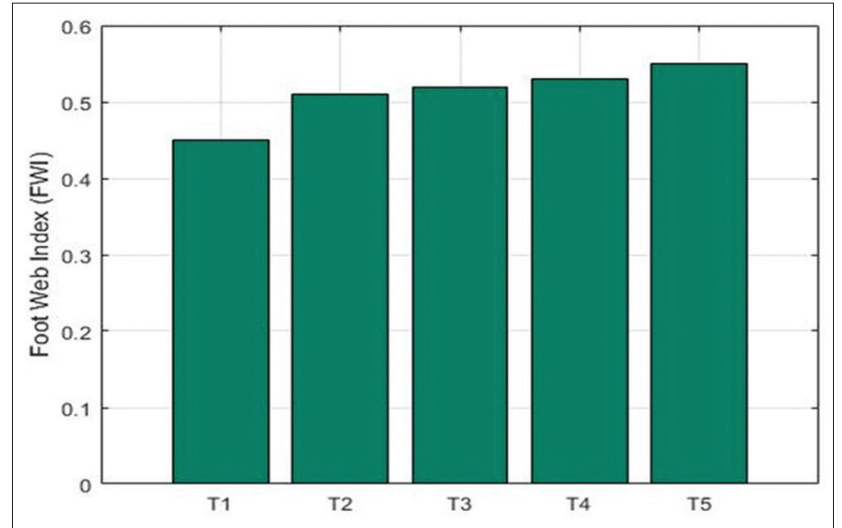

Figure-1: Cell-mediated immune response to phytohemagglutinin-P $(\mathrm{mm})$ in broilers under different dietary treatment.

titer in chicken post-immunization when fed with probiotic containing Lactobacillus. High level of HI titer due to the feeding of probiotic and prebiotic in broilers was reported by several authors [2,25-27]. The primary function of the immune system is to identify and eliminate pathogens [28], and this may be enhanced by administering probiotics that stimulate the local immune system [29]. The most likely reasons for Lactobacillus to increase the antibody titer in the present study might be due to the competitive exclusion of pathogens through competition of receptor sites, production of volatile fatty acids that are inhibitory of certain enteric pathogens, productions of bacteriocins or competition with pathogens, and native flora for limiting nutrients or stimulation of a host innate immune response [30].

The present study is in agreement with other authors who reported no significant increase in $\mathrm{CBH}$ response to PHA-P while feeding broilers with probiotic, a prebiotic, and acidifier either individually or in combinations [27]. Stringfellow et al. [31] and Mahmoud et al. [32] observed the lymphocytes from vaccinated broilers treated with probiotic to have greater $(\mathrm{p}<0.05)$ cell proliferation when compared with the negative control group. Patel [33] reported that the CMI response always exhibited the presence of serological immune response and vice versa and an increase or decrease in the level of CMI response did not always correspond to an increase or decrease in the level of serological immune response. The results 
of HI and PHA-P tests were independent of each other, and no correlation was found. It was also evident that the cell-mediated immunity played a decisive role in defense mechanisms against ND infection in broilers.

\section{Conclusion}

The L. reuteri PIA16 isolated from the gut of Assam indigenous chicken when fed singly and along with MOS to broiler chickens were found to enhance the immunity traits, namely, humoral immunity and CMI response of the broiler chickens. Therefore, supplementation of $L$. reuteri PIA16 along with MOS in commercial broiler chicken ration as probiotic and prebiotics may be proposed for enhancing immunity of the flock, lowering mortality, and boosting the production.

\section{Authors' Contributions}

DS, GKS, JDM, NK, JKT, and BNS designed the study. GG carried out the research study. PD helped in the study. GG wrote the manuscript. DS, PD, and JDM reviewed and corrected the manuscript. All authors read and approved the final manuscript.

\section{Acknowledgments}

The authors acknowledge the Department of Biotechnology, Ministry of Science and Technology, the Government of India, for funding the study (Grant No. BT/374/NE/TBP/2012 Dtd.07.01.2013).

\section{Competing Interests}

The authors declare that they have no competing interests.

\section{Publisher's Note}

Veterinary World remains neutral with regard to jurisdictional claims in published institutional affiliation.

\section{References}

1. Baurhoo, B., Ferket, P.R. and Zhao, X. (2009) Effects of diets containing different concentrations of mannanoligosaccharide or antibiotics on growth performance, intestinal development, cecal and litter microbial populations, and carcass parameters of broilers. Poult. Sci., 88(11): 2262-2272.

2. El-Sissi, A.F. and Mohamed, S.H. (2011) Impact of symbiotic on the immune response of broiler chickens against NDV and IBV vaccines. Glob. J. Biotech. Biochem., 6(4): 186-191.

3. Mohiti, A.M., Hosseini, S.A., Lollahian, H. and Shariatmadari, F. (2007) Effect of probiotics, yeast, Vitamin $\mathrm{E}$ and Vitamin C supplements on performance and immune response of laying hen during high environmental temperature. Int. J. Poult. Sci., 6(12): 895-900.

4. FAO/WHO. (2001) Health and Nutritional Properties of Probiotics in Food Including Powder Milk with Live Lactic Acid Bacteria. Report of a Joint FAO/WHO Expert Consultation on Evaluation of Health and Nutritional Properties of Probiotics in Food Including Powder Milk with Live Lactic Acid Bacteria. FAO/WHO, American Cordoba Park Hotel, Cordoba, Argentina. p1-34

5. Helland, M.H., Wicklund, T. and Narvhus, J.A. (2004) Growth and metabolism of selected strains of probiotic bacteria in maize porridge with added malted barley. Int. $J$. Food Microbiol., 91(3): 305-313.

6. Haghighi, H.R., Gong, J., Gyles, C.L., Hayes, M.A., Sanei, B., Parvizi, P., Gisavi, H., Chambers, J.R. and Sharif, S. (2005) Modulation of antibody-mediated immune response by probiotics in chickens. Clin. Diagn. Lab. Immunol., 12(12): 1387-1392.

7. Huang, M.K., Choi, Y.J., Houde, R., Lee, J.W., Lee, B. and Zhao, X. (2004) Effects of lactobacilli and an acidophilic fungus on the production performance and immune responses in broiler chickens. Poult. Sci., 83(5): 788-795.

8. O'Dea, E.E., Fasenko, G.M., Allison, G.E., Korver, D.R., Tannock, G.W. and Guan, L.L. (2006) Investigating the effects of commercial probiotics on broiler chick quality and production efficiency. Poult. Sci., 85(10): 1855-1863.

9. Kabir, S.M.L. (2009) The role of probiotics in the poultry industry. Int. J. Mol. Sci., 10(8): 3531-3546.

10. Khan, R.U. and Naz, S. (2013) The applications of probiotics in poultry production. Worlds Poult. Sci. J., 69(3): 621-631.

11. Saleh, A.A, Hayashi, K., Ijiri, D. and Ohtsuka, A. (2014). Beneficial effects of Aspergillus awamori in broiler nutrition. Worlds Poult. Sci. J., 70(4): 857-864.

12. Gibson, G.R, Probert, H.M., Loo, J.A.E., Rastall, R.A. and Roberfroid, M.B. (2004) Dietary modulation of the human colonic microbiota: Updating the concept of prebiotics. Nutr. Res. Rev., 17(2): 259-275.

13. Ganguly, S. (2015) A comprehensive review on physiological and nutritional properties of prebiotics as poultry feed supplement. Octa J. Biosci., 3(1): 5-6.

14. Saleh, A.A., Amber, K., El-Magd, M.A., Atta, M.S., Mohammed, A.A., Ragab, M.M. and El-Kader, H.A. (2014) Integrative effects of feeding Aspergillus awamori and fructooligosaccharide on growth performance and digestibility in broilers: Promotion muscle protein metabolism. Biomed Res. Int., 2014(5): 946859.

15. Saleh A.A., Gálik, B., Arpášová, H., Capcarová, M., Kalafová, A., Šimko, M., Juráček, M., Rolinec, M., Bíro, D. and Abudabos, A.M. (2017) Synergistic effect of feeding Aspergillus awamori and lactic acid bacteria on performance, egg traits, egg yolk cholesterol and fatty acid profile in laying hens. Ital. J Anim. Sci., 16(1): 132-139.

16. Suganthi, R.U. (2014) The uniqueness of immunocompetence and meat quality of native chickens: A specialized review. World J. Pharm. Pharm. Sci., 3(2): 2576-2588.

17. Mengesha, M. (2012) Indigenous chicken production and their innate characteristics. Asian J. Poult. Sci., 6(2): 56-64.

18. Kalita, N., Gawande, S.S. and Barua, N. (2009) Production and reproduction performance of indigenous chicken of Assam under rural condition. Indian J. Poult. Sci., 44(2): 253-255.

19. Kim, G.B., Seo, Y.M., Kim, C.H. and Paik, I.K. (2011) Effect of dietary prebiotic supplementation on the performance, intestinal microflora, and immune response of broilers. Poult. Sci., 90(1): 75-82.

20. OIE. (2012) Manual of Diagnostic Tests and Vaccines for Terrestrial Animals. $7^{\text {th }}$ ed. OIE, France. p555-574.

21. Corrier, D.E. and De Loach, J.R. (1990) Evaluation of cell mediated, cutaneous basophil hyper sensitivity in young chicken by an interdigital skin test. Poult. Sci., 69(3): 403-408.

22. Kabir, S.M.L., Rahman, M.M., Rahman, M.B., Rahman, M.M. and Ahmed, S.U. (2004) The dynamics of probiotics on growth performance and immune response in broilers. Int. J. Poult. Sci., 3(5): 361-364.

23. Khaksefidi, A. and Ghoorchi, T. (2006) Effect of probiotic on performance and immunocompetence in broiler chicks. J. Poult. Sci., 43(3): 296-300.

24. Brisbin, J.T., Gong, J., Orouji, S., Esufali, J., Mallick, A.I., Parvizi, P., Shewen, P.E. and Sharif, S. (2011) Oral treatment of chickens with lactobacilli influences elicitation of immune responses. Clin. Vaccine Immunol., 18(9): 1447-1455.

25. Ghahri, H., Toloei, T. and Soleimani, B. (2013) Efficacy of antibiotic, probiotic, prebiotic and synbiotic on growth 
performance, organ weights, intestinal histomorphology and immune response in broiler chickens. Glob. J. Anim. Sci. Res., 1(1): 25-41.

26. Mahdavi, S., Zakeri, A., Mehmannavaz, Y. and Nobakht, A. (2013) Comparative study of probiotic, acidifier, antibiotic growth promoters and prebiotic on activity of humoral immune and performance parameters of broiler chickens. Iran. J. Appl. Anim. Sci., 3(2): 295-299.

27. Srinivas, G., Preetam, V.C. and Qudratullah, S. (2015) Effect of probiotic, prebiotic and acidifier either alone or in combination on immune status and $E$. coli count of broiler. Indian Vet. J., 92(5): 100-102.

28. Waititu, S.M., Yitbarek, A., Matini, E., Echeverry, H., Kiarie, E., Rodriguez-Lecompte, J.C. and Nyachoti, C.M. (2014) Effect of supplementing direct-fed microbials on broiler performance, nutrient digestibilities, and immune responses. Poult. Sci., 93(3): 625-635.
29. Fuller, R. (1989) Probiotics in man and animals. J. Appl. Bacteriol., 66(5): 365-378.

30. Gaggia, F., Mattarell, P. and Biavati, B. (2010) Probiotics and prebiotics in animal feeding for safe food production. Int. J. Food Microbiol., 141(1): S15-S28.

31. Stringfellow, K., Caldwell, D., Lee, J., Mohnl, M., Beltran, R., Schatzmayr, G., Fitz-coy, S., Broussard, C. and Farnell, M. (2011) Evaluation of probiotic administration on the immune response of coccidiosis-vaccinated broilers. Poult. Sci., 90(8): 1652-1658.

32. Mahmoud, S., Shukry, M. and Saad, M. (2013) Lymphocytic proliferation and interleukin-2 production in chickens supplemented with growth promoters. Res. Opin. Anim. Vet. Sci., 3(3): 68-72.

33. Patel, S.K. (1992) Studies on Immunomodulatory Effects of Levamisole in Ranikhet Disease Virus ( $\mathrm{R}_{2} \mathrm{~B}$ strain) in Chicks. M.V.Sc Thesis, IVRI, Izatnagar (U.P.), India. 